\title{
Is Technology Good for Us? A Eudaimonic Meta-Model for Evaluating the Contributive Capability of Technologies for a Good Life
}

\author{
Edward H. Spence
}

Received: 21 September 2011 / Accepted: 17 October 2011 / Published online: 30 November 2011

(C) The Author(s) 2011. This article is published with open access at Springerlink.com

\begin{abstract}
The title refers to the question addressed in this paper, namely, to what degree if any technology, including nanotechnologies, in the form of products and processes, is capable of contributing to a good life. To answer that question, the paper will develop a meta-normative model whose primary purpose is to determine the essential conditions that any normative theory of the Good Life and Technology (T-GLAT) must adequately address in order to be able to account for, explain and evaluate the Contributive Capability of Technology for a Good Life (CCT-GL). By CCT-GL understand the capability of any technological product or process in its design and/or its use to contribute in some way, if any, to the good life of individuals and society at large. In this paper, the all-embracing term "technology" will be used to refer to both the products and processes of different technologies.
\end{abstract}

Keywords Technology · Good life · Wisdom · Ethics · Justification · Motivation · Sustainability Eudaimonia

E. H. Spence $(\bowtie)$

School of Communication and Creative Industries, Charles Sturt University,

Panorama Avenue,

Bathurst NSW 2795, Australia

e-mail: espence@csu.edu.au

\section{Introduction}

In an entry in the International Encyclopedia of Ethics ("Ethics of Nanotechnology") John Weckert [9] writes that,

Nanotechnologies, ...involves consideration of what ought to be researched and developed and whether the precautionary principle should be applied in some areas, and this in turn encourages examination, or re-examination, of some basic issues in the ethics and philosophy of technology and science: What is the purpose of technology? Can technological research and development be directed externally, and if it can be, should it be, and by whom? What is human flourishing, or "the good life", and how can technology contribute to this? These questions are larger than nanoethics but if the ethics of nanotechnology are to be discussed usefully, they cannot be separated from those discussions.

I concur fully with that assessment and its sentiment concerning not only nanotechnologies but all technologies, and particularly emerging technologies more generally. The primary aim of this paper is to address a general question in the philosophy of technology, namely, to what degree if any, technology, 
including nanotechnologies, in the form of products and processes, is competent in contributing to a good life. To answer that question, the paper will develop a metanormative model whose primary purpose is to determine the essential conditions that any normative theory of the Good Life and Technology (T-GLAT) must adequately address in order to be able to account for, explain, and evaluate the Contributive Capability of Technology for the Good Life (CCT-GL). By CCT-GL understand the capability of any technological product or process in its design and/or its use to contribute in some way, if any, to the good life of individuals and society at large.

In this paper, the all-embracing term "technology" will be used to refer to both the products and processes of different technologies, including nanotechnologies. Insofar as the central meta-question addressed in this paper, whether and how technologies contribute to a good life, applies to all technologies, it also applies to nanotechnologies. For their value will also be assessed on the basis of their capability for contributing to a good life. So any adequate theory of the Good Life and Technology should be capable of evaluating all technologies, including nanotechnologies.

There are at least two necessary methodological meta-conditions that any normative theory of the Good Life and Technology (T-GLAT) must meet. I will refer to those conditions as the formal condition and the material condition.

\section{The Formal Meta-Condition}

The formal meta-condition characterizes the necessary structural form of a T-GLAT's theoretical framework. It comprises at least three general normative categories that any T-GLAT must of necessity include within its theoretical framework, so as to be both theoretically and practically adequate. Those formal normative categories are motivation, justification and compliance. For if it lacks justification rational agents will have no reason to be convinced of its rational authority and if it lacks sufficient motivation, agents will not be pre-disposed to act in accordance with its prescriptions. Therefore, rational agents shall have no reason to offer their rational allegiance to a T-GLAT that lacks rational cogency. Finally, compliance is practically necessary if the prescriptions of a T-GLAT are to be capable of leading to social and political action through
T-GLAT informed policies. In summary the three formal meta-conditions are:

I. Justification - that which is adequately provided by rational arguments, capable of convincing any putative rational agent that they have good rational reasons or grounds for accepting and acknowledging the rational authority of certain precepts, rules, principles and values.

II. Motivation - that which motivates any putative rational autonomous agent to accept and acknowledge certain precepts, rules, principles and values, and moreover be adequately motivated to act in accordance with them.

III. Compliance - both motivation and justification are necessary for actual compliance with any T-GLAT so that it results in action or practice but not sufficient. This is because of at least two reasons: Firstly, weakness of the will of individual agents (individual akrasia) or weakness of the will of a collective or group of individuals (social akrasia); and secondly, lack of political will in the form of the inadequacy or lack of appropriate policies that encourage and promote compliance with adequate policies, informed and supported by any T-GLAT, which otherwise meets the motivation and justification conditions.

\section{The Material Meta-Condition}

The material condition characterizes the necessary content that any T-GLAT must address and include, both in its conceptual explanation and practical application. It comprises at least eight essential minimal conditions that any T-GLAT that seeks to evaluate the Contributive Capability of any Technology to the Good Life (CCT-GL) must adequately address:

\section{Capacity to address desires}

2. Capacity to meet needs

3. Capacity to provide means-ends satisfaction (instrumental satisfaction)

4. Capacity to contribute to valuable-ends

5. Capacity to preserve and promote moral rights

6. Capacity to be sustainable

7. Capacity to lead to the attainment of eudaimonia

8. Capacity to be practical in providing the ground for formulating policies in enabling compliance through its implementation and application. 
These material conditions will be explained in more detail in Section "Determining the Adequacy of Theories of the Good Life and Technology".

The Two Theses of the Paper in Summary

The above schema shows in outline how the formal conditions of justification, motivation and compliance are expressed and closely inter-linked contextually with the eight material conditions of the meta-model proposed. Using this meta-model the paper will argue for and support two inter-related theses:

(A) Any Theory of the Good Life and Technology (T-GLAT), whether desire-satisfaction theory, objectivist theory or capability theory, amongst others, must be capable of at least addressing and accounting for the two formal and material meta-conditions outlined above. Insofar as any T-GLAT fails to do so, it is not an adequate theory.

(B) An adequate T-GLAT theory to be proposed in this paper is the Eudaimonic Model for Evaluating the Goodness of Technology (EMEGOT) based on the notion of Wisdom [4]. The paper will provide arguments to demonstrate and support the case for such a theory but without excluding the possibility that other theories that meet the necessary formal and material conditions outlined above might also prove successful. As such, the paper takes a pluralistic methodological approach to the research question addressed in this paper.

\section{Determining the Adequacy of Theories of the Good Life and Technology}

Theories of the good life and technology (T-GLAT theories) irrespective of their specific content are collectively defined in this paper as theories whose primary purpose is to demonstrate how technologies (any technology) contribute to a good life. These theories seek to address the theoretical question posed in this paper, namely, whether and in what manner technologies are good for us in enabling us to live good lives. A basic theoretical assumption in this paper is that insofar as technologies are designed for the purpose of improving our lives then they must in some way contribute to the goodness of our lives.
That is, technologies must, at least in some minimal sense, make a contribution in enabling us as individuals and as a society to live a good life. For if they made no such contribution, what would they be good for? Such technologies would be at best useless or at worst, bad. However, given the aforementioned material condition of sustainability even a technology that was not directly bad for us could still be viewed as bad in some minimal sense if it was shown not to be sustainable.

\section{What is a Good Life?}

We can say quite reasonably that a good life generally is one that is at least minimally capable of enabling a person to attain self-fulfilment, ${ }^{1}$ well-being or happiness. I will for methodological convenience use the general term eudaimonia ${ }^{2}$ to include and refer to all those concepts collectively whilst maintaining the original intended meaning for that term by the ancient Greek philosophers, including Plato, Aristotle, and the Hellenistic philosophers and in particular the Stoics and the Epicureans ([7], Ch. 10). Although those philosophers might have explained the notion and attainment of eudaimonia in different ways they all at least agreed that the virtues were essential for the attainment of a eudaimonic or a flourishing life and moreover the virtues were constitutive of such a life. For insofar as eudaimonia is our ultimate object in life as Aristotle claimed, it is difficult to conceive a life that was not at least capable of leading to the attainment of eudaimonia, as good - what would it be good for if it were incapable of at least in principle enabling one to realize one's ultimate objective in

\footnotetext{
${ }^{1}$ For an extensive discussion of self-fulfillment and how it relates to a good life see [2]. In his [7] (Chapter 10), Spence argues that Gewirth's theory of self-fulfillment is very similar in key aspects to Stoic eudaimonia.

${ }^{2}$ For the purpose of this paper I will use the notions of eudaimonia and eudaimonic pluralistically as being potentially compatible with various different theories of the good life, including hedonistic, desire-satisfaction and objective-list theories among others. Simply put, as indicated earlier, the notion of a good life used in this paper is a good life that is in principle capable of leading to the attainment of eudaimonia. As such, any theory of a good life capable of leading to eudaimonia can at least in theory and upon further demonstration be considered a eudaimonic life. My own theoretical preference is a eudaimonic life that includes the virtues but that need not exclude other theories capable of also leading to the attainment of eudaimonia (its overall axiological goodness).
} 
life? For the purpose of this paper I will therefore define a goof life as any life that is demonstrably capable of contributing to the attainment of eudaimonia (the collective term for well-being, happiness and self-fulfilment).

Formal and Material Conditions for Adequacy

\section{Formal Conditions}

Any T-GLAT to be adequate must satisfy as mentioned earlier both a formal and a material condition. To be formally adequate it must be rationally justified, motivating and practical in the sense of being capable of resulting in compliance. Justification generally in decision-making is intended to provide convincing if not conclusive rational reasons for selecting one course of action rather than another and in the case of a T-GLAT, rational reasons for selecting a particular T-GLAT rather than another. Justified reasons alone, however, are not sufficient to guide rational action. That is because rational action requires that the rational reasons of justification must also be motivating reasons. For if justificatory reasons are not motivating they can't be practical and if they can't be practical they are not action-guiding and hence cannot play a role in the decision-making process. Thus, the decision-making process requires reasons for action that are at once justificatory and motivating.

A crucial point with regard to motivation, however, is that justificatory reasons need only be capable of motivating action. They need not and cannot also be expected to motivate action in every single instance. Although capable of motivating action in normal rational agents, motivating justificatory reasons may nevertheless fail in some instances to motivate particular agents to act.

In sum, justificatory reasons will count as motivating and thus practical and action guiding if they are capable of motivating a normal rational person to act in a certain way, specifically, for the purposes of this paper acting in giving their rational ascent to a particular T-GLAT.

In addition, any T-GLAT must be adequately practical in enabling compliance through informing policies that can promote its implementation. For a theoretically adequate T-GLAT that met both the justification and motivation formal conditions but was impractical in its application would not succeed in meeting the formal compliance condition. It would thus prove insufficient in satisfying its material conditions as specified above.

\section{Material Conditions}

To reiterate, the identified material conditions that any T-GLAT must address and satisfy for adequacy are the following:

1. Capacity to address desires;

2. Capacity to meet needs;

3. Capacity to provide means-ends satisfaction;

4. Capacity to contribute to valuable-ends

5. Capacity to preserve moral rights

6. Capacity to be sustainable

7. Capacity to lead to the attainment of eudaimonia

8. Capacity to be practical in providing the ground for formulating policies in enabling compliance through its implementation and application.

Roughly, conditions 1 to 4 primarily provide the context and drive motivation, and 4 to 6 primarily provide the context and drive justification. Conditions 7 and 8 provide at once the context for motivation and justification and condition 8 carries most of the weight for providing adequate compliance in terms of the practical implementation of a T-GLAT. Thus in order to be capable of motivation (a necessary formal condition) any T-GLAT must be capable of evaluating if and to what degree any technology addresses and accounts for the desires, needs, mean-end-satisfaction (or instrumental strategic thinking), and the valuableends (how valuable are the designated ends or goals promised or afforded by any technology) of actual agents.

In addition, any T-GLAT must be capable of providing adequate justification (also a necessary formal condition) of why such motivating states are reasonable on the basis of good reasons supporting those motivating states. Moreover, any T-GLAT must also be capable of accounting for and providing adequate justification of how and to what degree any technology preserves the basic minimal moral rights owed to every individual person, how and to what degree any technology is sustainable, and finally, how and to what degree any technology is capable of contributing to our individual and collective eudaimonia as a society. 


\section{A Eudaimonic Model for Evaluating the Goodness of Technology (EMEGOT)}

In this section I will propose and defend a eudaimonic model for evaluating the contribution that technology makes to the good life (its eudaimonic goodness). In asking the question, "what is technology good for", we can begin by saying that technology has generally some instrumental goodness as a means to attaining some functional goal or purpose. The instrumental goodness of an aeroplane, for example, lies in its capacity to transport passengers across the globe in less time than any other available means of commercial transport, such as boats and trains.

\section{Intrinsic but Conditional Goodness}

Technological products and artefacts have some minimal intrinsic value and goodness by virtue of their designed-in-agentive-purposiveness (DiAP). It is conditional on evolving human values and needs but technologies have no unconditional value or goodness in themselves [5].

Technology has minimal intrinsic but conditional value only to the extent that it contributes to meeting some specified functional human goals or purposes. So insofar as technology is not good simpliciter, it is good only to the extent that it has the capacity to contribute to the human good. People have a vast array of different instrumental goals to which technology can contribute as a means of achieving those goals. Is there one ultimate goal that all people value and desire as an end in itself? It is reasonable to assume that most if not all people aspire to have a good life capable of contributing to the attainment of eudaimonia (self-fulfillment; well-being; happiness; flourishing). This is in keeping with the Eudemonist Axiom, the view that "happiness is desired by all human beings as the ultimate end or telos of all rational action" ([1], 255). ${ }^{3}$

Undoubtedly technology contributes in countless ways to the good life instrumentally in meeting evolving needs, desires and valued individual and collective ends such as transportation, health, wealth, power, communication, etc. How can we normatively

\footnotetext{
${ }^{3}$ Brink attributes the Eudemonic Axiom to Gregory Vlastos in Vlastos [8] Socrates: Ironist and Moral Philosopher (Ithaca: Cornell University Press) p. 203.
}

evaluate technology's variable instrumental contributions to the good life? In what follows I will argue that the answer lies in technology's capability to contribute to the attainment of a good life. What value can we use to normatively evaluate technology's capability in contributing to a good life (CCT-GL)?

Wisdom as the Evaluative Principle for Assessing the Contributing Capability of Technologies for a Good Life

Insofar as the ultimate goal of a good life is the attainment of eudaimonia we can evaluate a technology's CCT-GL by ascertaining its capacity for contributing to a good life for the attainment of eudaimonia: A technology's capacity to contribute to a good life is its Eudaimonic Value. A technology's eudaimonic value therefore relates and is directly proportional to its capacity to contribute to a good life, capable of leading to the attainment of eudaimonia. In this paper I shall demonstrate that a technology's eudaimonic value can be determined directly by the application of a model based on the notion of Wisdom.

In the first instance I define wisdom as a type of meta-knowledge and an enabling second-order reflective virtue whose application is capable of guiding one in conceiving and discovering what a good life is and applying that knowledge in its active pursuit for the attainment of eudaimonia. Wisdom provides the overall answer to the question of why we need to design and use technologies in general: Because they are capable of contributing to human eudaimonia. In addition, wisdom enables us to evaluate the capacity of specific technologies to contribute to a good life for the attainment of eudaimonia.

Wisdom as a type of meta-knowledge provides why-answers - why design and use certain technologies in the first place; and as an enabling metaaxiological-virtue for conceiving what a good life is for the attainment of eudaimonia, wisdom provides how-answers - how to use those technologies in pursuit of a good life for the attainment of eudaimonia. Therefore, wisdom provides a theoretical and practical model for evaluating why and how certain technologies are good for us by ascertaining their capability for contributing to a good life for the attainment of eudaimonia. This is essentially the core argument of this paper. 
In what follows, I shall examine more closely how technology (understood as a collective term for all technologies) can be directly related to the notion of a good life via the concept of wisdom. Insofar as wisdom is a primary and essential condition for an individual in (a) determining what a good life is or ought to be (meta-knowledge- that and metaknowledge-why); (b) a primary and essential condition in providing us with guidance and direction, both as individuals and societies generally, of how to live such good lives; and (c) wisdom, as a reflective metavirtue, is a disposition of character that practically enables us to live such good lives for the attainment of eudaimonia (meta-knowledge-how); to what extent and in what ways, if any, can wisdom provide guidance in identifying and evaluating the degree by which technology contributes to the good life for the attainment of eudaimonia?

The paper posits that one direct way of evaluating the value of technology and its capacity to contribute to a good life generally (its overall axiological goodness) is by determining the degree to which it contributes or is capable of contributing to the attainment of a good life: epistemologically (its capacity to yield knowledge); ethically (its ability to contribute to the moral good of others both negatively by not causing unjustified harm to others, and positively by causing positive good for others); and eudaimonically (its capacity to contribute to both the conception and the attainment of a good life for the attainment of eudaimonia). The paper will show that in order to achieve that theoretical objective the notion of wisdom ${ }^{4}$ is essential.

In sum, insofar as the ultimate purpose of a good life is the attainment of eudaimonia then wisdom, which informs the conception of a good life and directs its active pursuit for the attainment of eudaimonia, is an essential condition for both the conception and the attainment of a good life.

As the essential condition for both the conception and guided active pursuit and successful achievement of the good life, wisdom is therefore established as an essential conceptual link between technology and the good life, and in particular for evaluating the eudaimonic contribution that various technologies make to a good life. This, in turn, allows us to

\footnotetext{
${ }^{4}$ For an extensive discussion of what wisdom is and some different types of notions of wisdom see Spence [4].
}

determine some of the generic implications and ramifications of technology for the conception of a good life, in particular, a eudaimonic conception of a good life. However, as Kekes points out, "the eudaimonic conception of a good life is not to be understood as the endorsement of a particular form of life. It is rather a regulative ideal that specifies some general conditions to which all good lives must conform" [emphasis added] ([3], p. 24).

The eudaimonic account of a good life canvassed in this paper is broadly speaking pluralistic as it is in principle compatible with other different conceptions of a good life that meet the same necessary general conditions to which any notion of a good life must conform. For example, insofar as hedonistic, desiresatisfaction and objective list theories of the good life meet the minimal conditions for both specifying what a good life is as well as providing the enabling conditions for its practical realization, then they too can be aligned broadly to the notion of wisdom developed in this paper. To the extent that they meet those conditions, they too can be used to determine the contributive capability of technologies to a good life.

\section{Wisdom as Meta-technology of the Self}

Insofar as technologies with a positive eudaimonic value are contributive instrumental means to the end or telos for having a good life, and wisdom is the meta-knowledge (second-order knowledge) for providing the conception of a good life and guiding its realisation, wisdom can be considered as a metatechnology of the self. For it provides both the theoretical and practical means for the conception, design and realisation of a good life for the end for attaining eudaimonia. The means to the realisation of a good life may include and often does include firstorder technologies such as computers, for example. If computers can be considered as extensions of the self then the degree by which they form part of the self also becomes a question concerning wisdom. How and to what degree computers as extension of the self, contribute to a good life for the attainment of eudaimonia.

To the extent that first-order technologies provide the means for making our lives better by contributing to a good life and wisdom provides the means as a meta-technology of the self for enabling human beings 
to have a good life for the attainment of eudaimonia, then clearly wisdom as a meta-technology should direct the choice and design of first-order technologies; for those will be the technologies that will have the highest eudaimonic value and the highest capacity for making a positive contribution to a good life.

\section{A Sustainable Good Life and Technology ${ }^{5}$}

A good life in the $21^{\text {st }}$ century should be a sustainable good life. In the past the issue of sustainability and that of a good life could have been perceived as two conceptually distinct and practical issues that could have been dealt with independently of each other. However, that is no longer the case. Since at least the Kyoto Protocol the problem of sustainability has been the central focus of social, scientific and political debate. As examples of sustainable technologies, consider the dual-flush toilet and shower-heads that are designed for saving water, recycling of water, recycling of consumables, such as plastic, glass and paper, installation of electrical household appliances as well as the design and production of transport vehicles including cars, buses, trains and aeroplanes that are more energy efficient (the new Dreamliner made entirely of carbon fibre for more energy efficiency is a case in point).

In all these examples, what seems crucial, however, is the role that people's desires play in motivating compliance with energy saving technologies. People must want to comply and moreover be persuaded that there are justified reasons for complying with such technological energy-saving policies and practices for the policies and practices to work. The installation of an energy-consumption metre inside one's home, for example, that allows the monitoring of the overall energy consumption of a household would be a practical technological device for encouraging compliance with efficient energy use. Crucially, however, individuals must first be motivated to want to install such a device within their homes. Such initial motivation can best be primed by rationally targeting the consumers' desires [6].

The eudaimonic model for evaluating the goodness of technology (EMEGOT), which relates the goodness of technology to its eudaimonic value though its

\footnotetext{
${ }_{5}^{5}$ For an extensive discussion of a sustainable good life see Spence [6].
}

capability to contribute to a good life, is able to motivate people's rational desires for a good life. It does so though its ability to demonstrate that, although life is not indefinitely sustainable, an unsustainable life for a projected defined period cannot be good as it is potentially self-defeating and incapable of leading to eudaimonia. By creating its own unsustainable desires, by an ever increasing plethora of technological devices that consume rather than preserve scarce resources and are thus nonsustainable in a technological world of ever diminishing resources, it would be wise to design and make technologies that are compliant to the conditions for a sustainable good life. This could be accomplished by designing technologies that are capable of contributing to a sustainable good life for the attainment of eudaimonia.

We need to shift the focus from the epistemic value of technologies, their ability to contribute to knowledge or information (as in the case of communication and information technologies) for knowledge's sake, to that of their eudaimonic value, their ability to contribute to a sustainable good life capable or leading to eudaimonia. To do that, we need to design technologies wisely and that in turn requires that we enable ourselves to become wiser through designing and promoting meta-technologies of the self that enhance our capacity for wisdom. Revisiting and revitalising the ancient philosophies of Plato, Aristotle, the Epicureans, the Stoics and even the Sceptics, that were essentially practical philosophies of the good life for the attainment of eudaimonia, might be a good place to start.

\section{Application of the Eudaimonic Model for Evaluating the Goodness of Technologies}

The primary aim of this paper has been to develop a meta-normative model whose primary purpose is to determine the essential conditions that any normative theory of the Good Life and Technology (T-GLAT) must adequately address in order to be able to account for, explain and evaluate the Contributive Capability of Technology for the Good Life (CCT-GL). I have argued in section (3) that my prosed Eudaimonic Model is an adequate normative model for evaluating the contribution that technology makes to the good life (its eudaimonic goodness) for it meets both the 
essential meta-formal as well as meta-material conditions for such an axiological evaluation. However, as I emphasized above, my choice of a eudaimonic model based on the concept of wisdom, does not of itself exclude other possible normative models that may also prove adequate. It is beyond the scope of this paper, however, to apply the Eudaimonic Model to evaluate the capability of specific technologies to contribute to a good life - that is, to evaluate their specific CCT-GL.

It is reasonable to assume pending a further detailed examination that different technologies will have a variable CCT-GL — some higher, others lower — which will vary according to the specific function and use of those technologies. For example, the use of some communication and information technologies, such as the internet and smart-phones, by some individuals may prove self-defeating by causing more harm than good to those individuals. Take for instance the practice of sexting. In the recent case of the USA ex-congressman Anthony Wiener, it forced his resignation from office and spelled the end of his political career. It can be said that the specific use of that particular technology in those circumstances, was not conducive to the good life of Weiner (at least as he may have conceived it to be at that time). It may also have not been conducive to the good life of many other Internet and smart-phone users who have similarly engaged in self-defeating digital communication behaviour resulting in unintended self-harm.

Other technologies such as automated predator drones used in war will require a more complex analysis to determine their CCT-GL. However, their capability for contributing to a good life should still be the overall guiding evaluative principle to be applied in normatively assessing those technologies. Determining the different general types of technologies and their corresponding CCT-GL according to their different functions and uses will make a worthwhile topic for further research.

\section{Conclusion}

The eudaimonic model for evaluating the goodness of technology (EMEGOT) proposed in this paper is an adequate theory for evaluating the capability of technologies to contribute to a good life because it meets the essential formal and material conditions of an adequate theory of the Good Life and Technology (T-GLAT).

First, it meets the formal conditions of justification, motivation and compliance: Justification, because the three essential categories that comprise the notion of wisdom, the epistemic, the ethical and the eudaimonic, are at once the essential normative categories required for evaluating the capability of technologies for contributing to a good life; Motivation, because the notion of wisdom is capable of linking the normative evaluation of technologies directly to the notion of a good life and eudaimonia, which are highly valued practical objectives for most peoplefor most people wish to have a good life and to be happy; Wisdom also satisfies the compliance condition. For by being capable to directly link the contribution that technologies make to a good life, wisdom offers a practical measure for developing policies that can direct and guide the design of emerging technologies (including nanotechnologies) according to their eudaimonic value for the well-being of society.

Second, EMEGOT is also capable of meeting the material formal conditions of an adequate theory. It can address and account for desires and needs in terms of both their instrumental means and final ends, since wisdom relates those to the two highly valued aspirational objectives of a good life and eudaimonia. Finally, EMEGOT is capable of addressing and accounting for the material conditions of moral rights and sustainability, for wisdom as a meta-reflectivevirtue also supports and promotes those essential material conditions. For as I have argued in this paper wisdom directs that a good life in the $21^{\text {st }}$ century and beyond must of necessity be a sustainable life.

With regard to nanotechnologies, EMEGOT seems particularly useful in evaluating their ability to contribute to a good life since some of the potential effects and consequences of some nanotechnologies cannot be assessed with any degree of certainty at present. For example, concern for the use of nanoparticles in cosmetics and sunscreens has been raised, as these particles can penetrate the skin and lodge in various parts of the body potentially causing harm such as inducing certain forms of cancer [9]. Though still unproven, such concerns should give us pause. We should more reflectively examine the potential risks associated with such nanotechnologies and evaluate their 
potential benefits not primarily in terms of what new knowledge they give rise to but primarily in terms of the potential contribution they make to a good life (their eudaimonic value).

Open Access This article is distributed under the terms of the Creative Commons Attribution Noncommercial License which permits any noncommercial use, distribution, and reproduction in any medium, provided the original author(s) and source are credited.

\section{References}

1. Brink D (1999) Eudaimonism, love and friendship, and political community. Soc Philos Pol 16:252-289

2. Gewirth A (1998) Self-fulfilment. Princeton University Press, Princeton
3. Kekes J (1995) Moral wisdom and good lives. Cornell University Press, Ithaca

4. Spence E (2011) Information, knowledge and wisdom: groundwork for the normative evaluation of digital information and its relation to the good life. Ethics Inform Tech 13 (3):261-275

5. Spence E (2010) Information ethics without metaphysics: a Neo-Gewirthian approach. Int J Tech Hum Interact 6(1):114

6. Spence E (2008) Groundwork for a neo-epicurean approach to a sustainable good life in a technological world. Australian Journal of Professional and Applied Ethics $10(1$ and 2):73-81

7. Spence E (2006) Ethics within reason: a neo-gewirthian approach. Lexington Books (a division of Rowman and Littlefield), Lanham

8. Vlastos G (1991) Socrates: ironist and moral philosopher. Cornell University Press, Ithaca

9. Weckert J (2013) Nanoethics. In: La Follette (ed) International encyclopedia of ethics, Wiley-Blackwell (accepted April 2011) 